\title{
Cytological Studies in Two Species of Dipcadi Medic. from India
}

\author{
V. N. Naik \\ Department of Botany, Marathwada University, Aurangabad, Maharashtra, India
}

Received April 19, 1973

The genus Dipcadi Medic. (Liliaceae) is represented in India by about eight species. Three of these are distributed in the Northern India, four are rather restricted to the Western India and one, namely D. montanum Baker, has a wider distribution. It is reported from the Northern India, Concan, Western Deccan (Hooker 1892) up to Belgaum in the South (Cooke 1907). It has now been collected from Aurangabad and its surrounding areas. Its occurrence in Orissa and other places in India, Africa and Madagascar as reported by Mahabale and Chennaveeraiah (1962) is not, however, supplemented by any published evidence.

Cytology of three African and three Indian species has been worked out so far. African species include $D$. serotinum with $2 \mathrm{n}=8$ (Sato 1942, Levan 1944), $2 \mathrm{n}=8+2-$ 16B (Resende and Franca 1946) and 2n=8+0-1B (Fernandes et al. 1948), $D$. glaucum with $2 \mathrm{n}=18$ (Darlington and Wylie 1955) and D. fulvum with $2 \mathrm{n}=34$ (Battaglia 1954). The Indian species include $D$. montanum with $2 \mathrm{n}=20, D$. saxorum with $2 \mathrm{n}=12$ and $D$. ursulae with $2 \mathrm{n}=20$ (Mahabale and Chennaveeraiah 1954, 1962).

\section{Materials and methods}

The bulbs and flower buds of $D$. montanum were collected from Aurangabad and the surrounding areas while those of $D$. saxorum were collected from its type locality near Bombay. Root tips were pretreated with colchicine $(0.01 \%)$. Materials were fixed in acetic-alcohol $(1: 3)$ and stained with aceto-orcein $(1 \%)$.

\section{Results}

There are two distinct cytological races of $D$. montanum in this area; one, with $2 n=12$ (Figs. 1a and 2a) and the other, with $2 n=10$ (Fig. 5). The former grows on a muddy substratum and is rather robust, with deep green leaves and greenish flowers. The latter grows on poor rocky substratum and appears rather stunted, with pale green leaves and whitish flowers. Both of them grow on table-lands and are difficult to distinguish by qualitative morphological characters.

The plants make their appearence after the first showers in the monsoon i. e. during the third week of June, leaves and flowers appearing simultaneously. Aerial shoot is ephemeral and the entire life cycle is completed by the end of August $(2 n=10)$ or September $(2 \mathrm{n}=12)$. Leaves in the both are narrow and $10-30 \mathrm{~cm}$ long. A solitary scape may be equally long or shorter with $15-20$ flowers in a raceme. The flowers in most cases wither and drop off while one or two capsules may develop fully in 
$5-10 \%$ individuals.

The forms with $2 \mathrm{n}=12$ have two very long $(5.3 \mu)$, four long $(4 \mu)$ and six very short $(1.5 \mu)$ chromosomes. All of them are acrocentric. The karyotype is asymmetrical and of a specialised type. Its absolute size is $35.6 \mu$ (Fig. 3a). Forms with $2 n=10$ have essentially the same karyotype with the deletion of one of the very short pairs and, therefore, have absolute size of $32.6 \mu$. No satellites have been

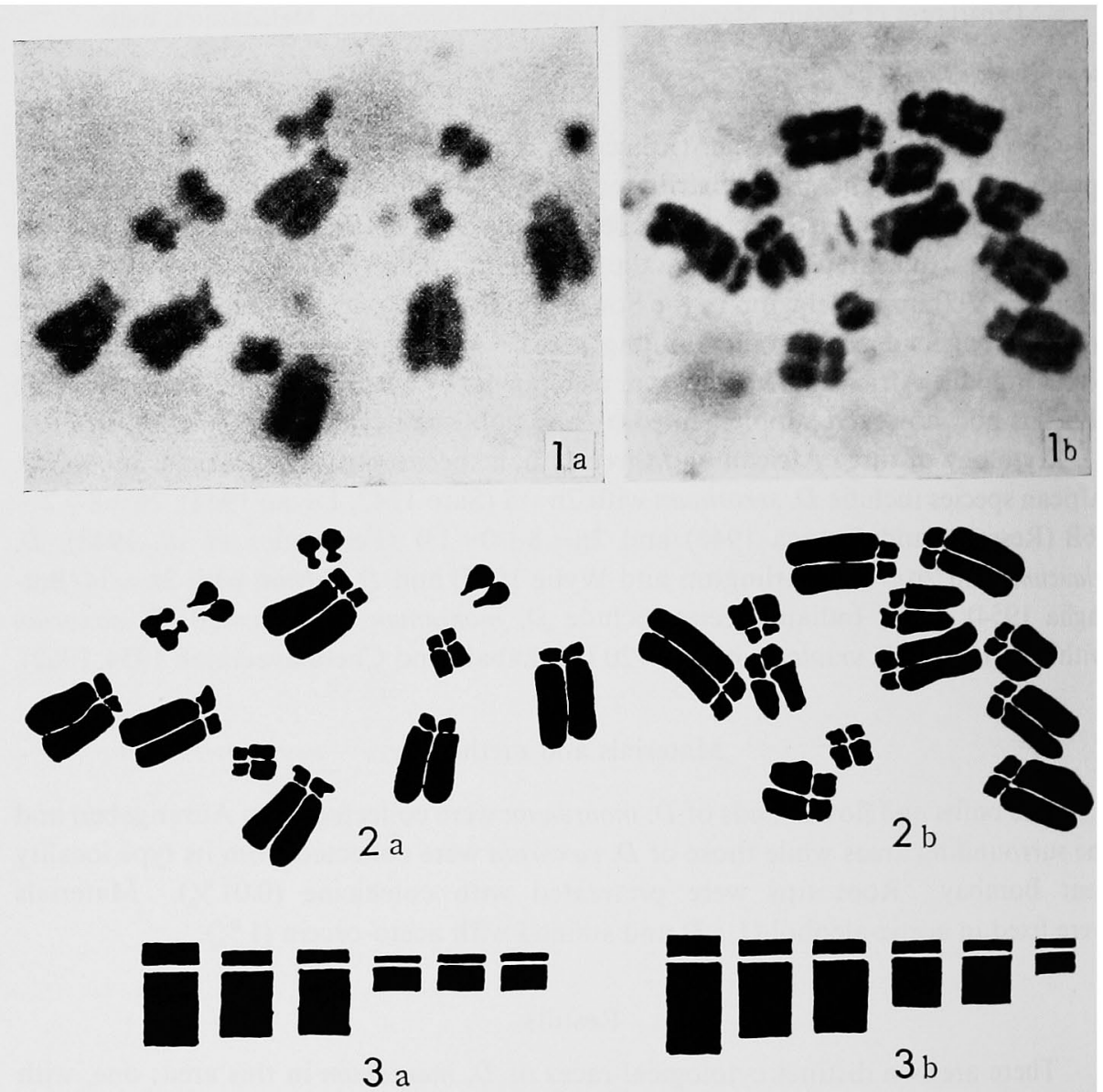

Figs. 1-3. 1, micrographs of root tips squashes of a, D. mantanum. b, D. saxorum. $\times 3000$. 2, camera lucida drawings of somatic chromosomes at metaphase. a D. montanum. b, D. saxorum. both $\times 3000$. 3: Idiograms of somatic chromosomes. a, D. montanum. b, D. saxonum.

observed in any of these forms. Most of the cells show two nucleoli. The karyotype of $D$. saxorum is similar to that of $D$. montanum (Figs. $1 \mathrm{~b}$ and $2 \mathrm{~b}$ ) but instead of having three very short pairs, it has two short pairs (each chromosome being $3 \mu$ long) and only one very short pair. Absolute size of the karyotype is $41.6 \mu$ (Fig. $3 \mathrm{~b}$ ).

Microsporogenesis in both the species is characterised by abnormal meiosis in large percentage of pollen mother cells, resulting in crumpled pollen. In about $5-7 \%$ of the flowers of $D$. montanum the meiosis was regular, showing six clear 
bivalents (Fig. $4 \mathrm{~b}$ ) in form with $2 \mathrm{n}=12$ and five in forms with $2 \mathrm{n}=10$. In D. saxorum also six clear bivalents were observed except in some PMC's where two univalents along with the normal complement were recorded (Fig. 4a). These additional univalents have not been observed in the mitosis of roots and are probably lost during this division. Laggards have not been noted in any of the forms studied. Microspore tetrads of various kinds viz. linear, T-shaped, decussate and isobilateral were observed, the last one being the most common. Fertile pollen grains are binucleate at anthesis, monocolpate and monosiphonous.

The fruit formation is very rare but when capsules develop they contain a large number of viable seeds. The propagation is mainly by underground bulbs.

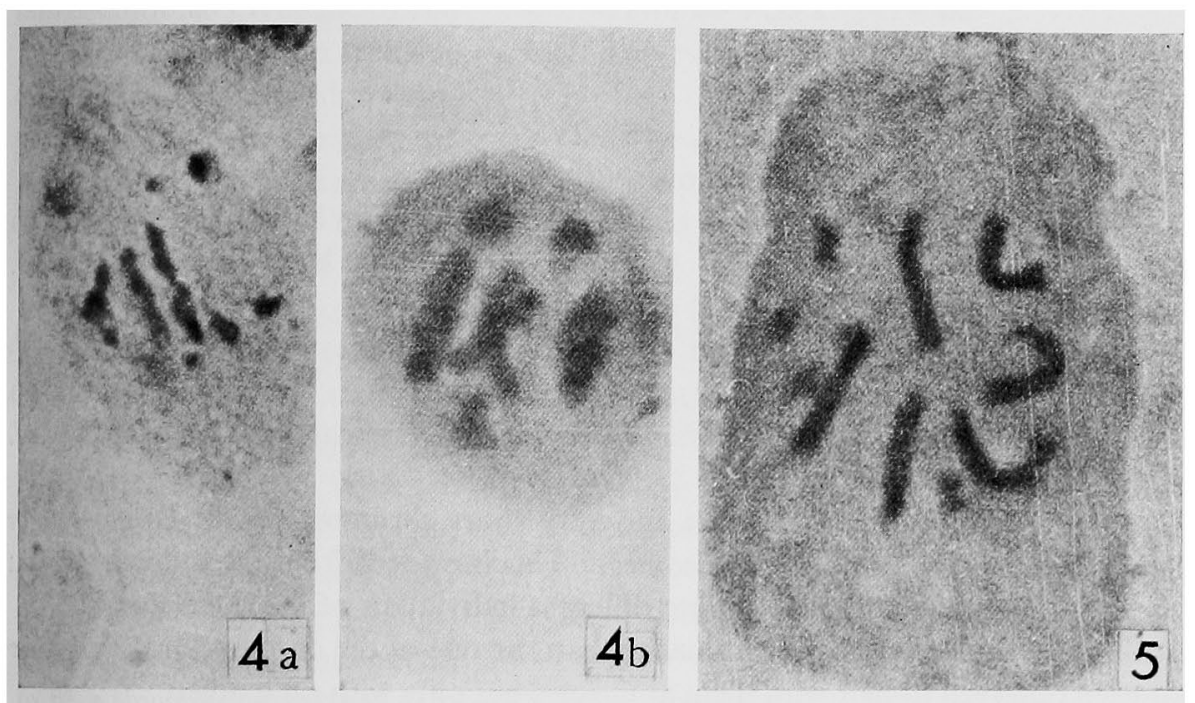

Figs. 4-5. 4, metaphase $\mathrm{I}$ in microspore mother cells. b, D. montanum $\mathrm{n}=6_{\mathrm{I}}$. a, D. saxorum $\mathrm{n}=6_{\mathrm{II}}+2 \mathrm{I}$. both $\times 3000$. 5 , somatic chromosomes in a form of $D$. montanum showing $2 \mathrm{n}=10$. $\times 3000$.

\section{Discussion}

The genus Dipcadi with over 40 species (Thiselton-Dyer 1898) is probably African in orgin and has migrated to India via N-W India. This is evident from a large number of species reported from Africa and a few species restricted to N-W and Western India. With one of the species, D. montanum, occurring in Aurangabad and its surroundings, the distribution of the genus can now be extended eastwards to the Deccan plateau. D. serotinum appears to be a connecting link since it occurs both in Africa and India.

From the presently available data, the basic number for the genus appears to be $x=4$ and all the other numbers viz. $x=5,6,9,10$ and 17 reported earlier are in most cases due probably to the presence of variable number of B-chromosomes. Polyploidy has not been recorded in any of the species studied so far. The possibility of polysomy and/or hybridization in the evolution of different species cannot be ruled out though there is no direct or indirect evidence in support of this assumption. 
The karyotypes in all the species studied are asymmetrical with acrocentric chromosomes. These features are suggestive of relatively advanced or specialised status of the genus. This is also correlated with specialized floral structure and vessels are advanced beyond a primitive level and rather specialized (Cheadle and Kosakai 1971).

Out of six different basic numbers of chromosome reported in the genus so far $\mathrm{x}=5,6$ and 10 occur in two species viz. D. montanum and $D$. saxorum. The details are as follows:

$$
\begin{aligned}
\text { D. montanum } & \\
2 \mathrm{n}=20 ; & 2 \mathrm{VL}+4 \mathrm{~L}+8 \mathrm{~S}+6 \mathrm{VS} \\
2 \mathrm{n}=12 ; & 2 \mathrm{VL}+4 \mathrm{~L}+6 \mathrm{VS} \\
2 \mathrm{n}=10 ; & 2 \mathrm{VL}+4 \mathrm{~L}+4 \mathrm{VS} \\
\text { D. saxorum } & \\
2 \mathrm{n}=12 ; & 2 \mathrm{VL}+4 \mathrm{~L}+4 \mathrm{~S}+2 \mathrm{VS} \\
2 \mathrm{n}=14 ; & 6 \mathrm{II} \text { as above }+2 \mathrm{I} .
\end{aligned}
$$

All the forms of $D$. montanum and $D$. saxorum have $2 \mathrm{VL}+4 \mathrm{~L}$ and at least two short or very short chromosomes. This happens to be the basic complement of $D$. serotinum $(2 \mathrm{n}=8=2 \mathrm{VL}+4 \mathrm{~L}+2 \mathrm{VS})$ also (Sato 1942$)$.

The number of these short and very short chromosomes appears to vary in different species as well as different forms of the same species. These have been shown to be B-chromosomes in D. serotinum (Resende and Franca 1946, Fernandes et al. 1948)

In all probablities, these short and very short chromosomes in $D$. montanum and $D$. saxorum are also B-chromosomes. This is evident from the following facts:

1. They vary in number among different individuals of the same species.

2. They are conspicuously smaller than the rest of the chromosomes and have not been observed to pair with them at meiosis but only with each other.

3. In D. saxorum they are seen at meiosis in PMC's but are probably lost at mitosis in roots.

4. There is no notable morphological variation in different cytological forms of the same species or even between two related species. The differences so far noted are all of quantitative nature only.

5. In natural population of $D$. montanum, forms with 4 and 6 very short chromosomes exist side by side in competition, although there is a minor edaphic preference.

It is too premature to predict anything in regard to the origin of the B-chromosomes in this genus. As there are two different sizes (short and very short) of chromosomes, they might have different origins in various species.

The habitat of the forms of $D$. montanum is also intersting in this connection. Forms with $2 n=20$ are found in Western India, where there is heavy rainfall and thus high humidity. Forms with $2 n=12$ and $2 n=10$ are found in semi-arid regions of Marathwada with very low rainfall and dry weather. Even from the two latter forms those with $2 n=12$ prefer muddy substratum and those with $2 n=10$ are seen growing on poor, rocky substratum.

The adaptive significance of these B-chromosomes in $D$. saxorum is obscure 
since both the forms $(2 n=12$ and $2 n=12+2 B)$ occur in the same locality.

It is clear that the genotypes in both the species discussed above are unstable at diploid level. This might be considered a step towards future polyploidy (Stebbins 1950). With the present knowledge no species can be considered an allo- or autopolyploid of any existing species.

The cytological studies in comparatively few species of this genus are not conclusively indicative of the variation patterns in the genus as a whole but certain evolutionary tendencies can be noted. For more reliable conclusions a detailed investigation of a large number of African and Indian species is essential.

Considering $x=4$ as the basic number for the genus and $2 n=8$ (D. serotinum type) as a basic karyotype $(2 \mathrm{VL}+4 \mathrm{~L}+2 \mathrm{~S}$ or 2VS) other karyotypes can be derived (Fig. 6). With the accumulation of more data on chromosome number, their morphology and breeding systems, all the Indian species may prove to be a single polytypic species.

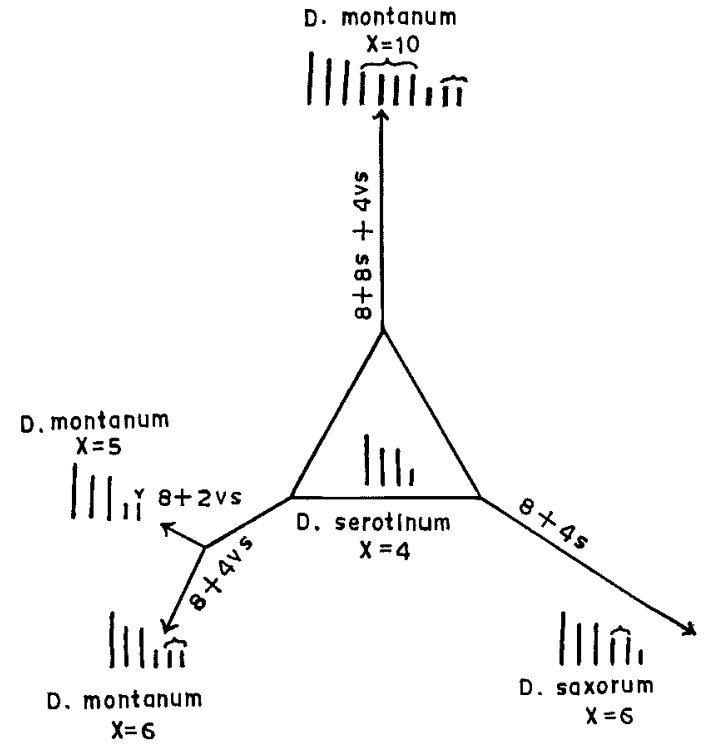

Fig. 6. Hypothetical evolutionary trends in karyotypes of $D$. montanum and $D$. saxorum from $D$. serotinum like ancestor.

\section{Summary}

The cytological details of $D$. montanum Baker and $D$. saxorum Blatter have been presented. Both these species are at diploid level. D. montanum has $2 \mathrm{n}=20,12$ and 10 , while $D$. saxorum has $2 \mathrm{n}=12$ and 14 chromosomes. Variable chromosome numbers in both the species are probably due to the presence of B-chromosomes.

Irregular behaviour of chromosomes at meiosis and poor stainability of large precentage of pollen grains indicate high degree of sterility in these species. Regular bivalents were observed only in about $5-7 \%$ of the PMCs.

Formation of fruits and the development of viable seeds is very rare and propagation appears mainly through underground bulbs. Both the species have unstable genotype and appear active from evolutionary stand point.

\section{Acknowledgements}

My grateful thanks are due to Prof. K. B. Deshpande of this department for providing all facilities for this work. I am deeply indebted to the Director, 
Royal Botanic Gardens, Kew for confirming the identification of my plant specimens, and to Dr. V.D. Tilak of Institute of Science, Bombay, for sending valuable material of $D$. saxorum and some rare literature.

\section{References}

*Battaglia, E. 1954. Caryologia 6: 63.

Cheadle, V. I. and Kosakai, H. 1971. Vessels in Liliaceae, Phytomorphalogy 21 (4): 320-333. Cooke, T. 1907. The Flora of the Presidency of Bombay Vol. 3 reprinted, India.

Darlington, C. D. 1956. Chromosome Botany and the Origins of Cultivated Plants. ed. 2, London.

— and Wylie, A. P. 1955. Chromosome Atlas of Flowering Plants, London.

*Fernandes, A., Gracia, J. and Fernandes, R. 1948. Mem. Soc. Bot. 4: 5.

Haines, H. H. 1924. Botany of Bihar and Orissa. Vol. III reprinted, India.

Hooker, J. D. 1892. The Flora of British India. Vol. VI, pt. 43 London.

*Levan, A. 1944. Hereditas 30: 217.

Mahabale, T. S. and Chennaveeraiah, M. S. 1954. Karyotypes in Dipcadi Medic. Curr. Sci. 23(2): $367-368$.

- and - 1962. Cytoembryology of Dipcadi montanum Baker. Proc. Nat. Inst. Sci. India 27 (4): 153-171.

*Resende, F. and Franca, P. da 1946. Portug. Acta Biol. 1: 289.

Sato, D. 1942. Karyotype alteration and phylogeny in Liliaceae and allied families. Japan J. Bot. 12: $57-161$.

Stebbins, G. L.(Jr.) 1950. Variation and Evolution in Plants, New York.

Thiselton-Dyer, W. I. 1898. The Flora of Tropical Africa. Vol. 7, pp. 516-523, London.

*Quoted from Darlington and Wylie 1955. 